\title{
Still Assembling Parts - The barriers to personalized genetics for pain management
}

\author{
Isabella Albanese \\ News Reporter (HSI 2014-2015)
}

Personalized medicine is an emerging concept in the practice of medicine that involves taking a patient-centered approach to disease prevention, diagnosis and therapeutic optimization using knowledge obtained from a patient's genetic profile. Pharmacogenomics, the specific practice of using genetic information to better predict individual patient variability to treatments is becoming increasingly relevant in the field of chronic pain management ${ }^{1}$. Chronic pain is characterized as pain lasting longer than 12 weeks, and is one of the most common reasons for patients to seek medical care $^{2}$. Despite its prevalence, in Canada, the management of both acute and chronic pain is considered inadequate. With an increasing number of pain medication-related deaths in Ontario ${ }^{3}$, long wait times at pain clinics across the country ${ }^{4}$, insufficient pain curricula taught in Canadian medical schools $s^{5}$ and underfunded research relative to the severity of the issue ${ }^{6}$, there are several aspects of pain management in the Canadian healthcare system that need improvement ${ }^{7}$. In addition, chronic pain has been estimated to cost Canadians approximately 6 billion dollars per year in direct costs, and this does not take into account the indirect costs such as decreased work productivity and a reduced quality of life ${ }^{8}$. Thus, the potential benefits on both an individual patient and societal level of approaching pain therapy and prevention in a personalized way are numerous. However, pain is a complex trait that is not only subjective and difficult to measure but also is influenced by many factors including, but not limited to, numerous environmental exposures, genetic variants, neuronal circuits, and physiological status such as inflammation and stress response. These factors present just some of the potential barriers to both personalized pain medicine, and pain management in general.

Dr. Jeffrey Mogil, a prominent pain genetics researcher at McGill University, focuses his research specifically on individual differences in pain sensitivity and susceptibility, analyzing both genetic and environmental aspects of this, as well as their interaction. Dr. Mogil says, "research in the field has shifted to becoming more and more translational". While he has had success implementing this in the behavioural study of pain differences, his most recent work on the capacity for mice to experience empathy for pain amongst familiar mice, and the reproducibility of this phenomenon among human subjects ${ }^{9}$, Dr. Mogil cites many barriers to pain genetics research becoming translational. When asked what the main barrier is to making pain genetics research translate to the bedside, Dr. Mogil answers with one word, "Complexity".

"It [pain genetics] could have turned out to be simple like with the BRCA1/2 genes (breast cancer 1 and 2, early onset) in breast cancer or the CFTR gene (cystic fibrosis transmembrane conductance regulator (ATP-binding cassette sub-family $C$, member 7 ) in cystic fibrosis, where there is one predominate gene responsible for the condition. But, there are a lot of other conditions like diabetes and increasingly, pain falls under this second camp of disorders that are vastly multigenic with hundreds of relevant genes."

Dr. Mogil brought up an excellent point about the complexity of pain genetics as there have been hundreds of genes associated with pain phenotypes and nociception, and the list continues to grow ${ }^{10}$. In fact, Dr. Mogil's research group recently published a study in which they examined the effects of pharmacologically targeting a 6-transmembrane splice variant of the $\mu$-opioid receptor gene in mice, and found that it produced potent analgesic effects ${ }^{11}$. The $\mu$-opioid receptor (MOR) is arguably the most important target in pain treatment, however despite the efficacy and widespread use of this target in treatment (e.g. morphine), there is a high rate of adverse events. In addition to having potent analgesic effects, Dr. Mogil's study found that specifically targeting 6-TM splice variants of the $\mu$-opioid receptor gene with synthetic compound iodobenzoylnaltrexamide (IBNtxA) also resulted in a vast improvement in side effects. It is postulated that 6-TM MOR's function is mediated through completely different cellular pathways than conventional MOR hence the wide variation in side effect profiles ${ }^{12}$. A major contributing factor to the adverse events associated with opioid use is 
individual variability, some of which may be explained by variations in the $\mu$-opioid receptor gene ${ }^{13}$. There have been single nucleotide polymorphisms (SNPs) associated with the 6TM and 7TM MOR variants. This is of potential clinical significance as clinical evaluation of functional genetic variants of $\mu$-opioid receptor gene locus may provide a clearer picture of inter-patient variability to opioid therapy, and may lead to the development of new pharmacological targets ${ }^{13}$. In addition to opioid receptor variants, there are several other categories of genes that have been implicated in pain genetics including, but not limited to serotonin receptors and transporters, pro-opiomelanocortin (POMC), cannabinoid receptors, adrenergic receptors, monoamine oxidase (MAO), interleukins as well as several growth factors and transporters ${ }^{14}$.

The analogy Dr. Mogil uses is as follows: "If you want to explain how a car works, one of the first things that you need to do is get the parts list of the car. The problem is that even when you have the parts list of the car, you still don't know how the car works. That is where we are in pain genetics. We are assembling the parts list, which needs to be done but is not going to explain the other things after that which are hard for me to even envisage at this point."

Despite the complexity and the many unanswered questions regarding pain genetics, there have been advances in the use of pharmacogenetics and personalized medicine in chronic pain management. A recent study by Linares et al. presents a clinical framework for assessing a patient's CYP2D6 phenotype ${ }^{15}$. Categorizing patients as CYP2D6 ultra-rapid metabolizer, extensive metabolizer, or poor metabolizer phenotypes using pharmacokinetic profiling allows for a safer and more efficient method of determining oxycodone dose thus decreasing the likelihood of adverse side effects ${ }^{15}$. This is an important first step in the integration of the use of individual genetic variations to pain and corresponding adjustments to clinical practice. There is still a long way to go in the classification of the genetic factors contributing to pain susceptibility and response to treatment. Despite this, it is essential that we move forward and continue to support research that aims to classify genetic explanations for pain variation and the potential clinical benefits of manipulating these targets.

Dr. Mogil is also a member of the Alan Edwards Center for Research on Pain (AECRP), an organization that brings together McGill University researchers from the Faculties of Medicine, Dentistry and Science as well as members from across the province, clinicians and clinical pain researchers for the united purpose of sharing new advances in pain research and fostering discussions on clinically relevant applications of this work. In the spirit of promoting translational research and the integration of basic research science and clinical practice, the AECRP's many initiatives include providing research grants and graduate scholarships, hosting bimonthly Journal Clubs, hosting Pain Day, which is an annual research conference on the study and treatment of pain, as well as weekly pain rounds in the Alan Edwards Pain Management Unit of the McGill University Health Centre. While there is undoubtedly a great deal of progress still to be made in the field of pain genetics, it is collaborative efforts like this that encourage the continued pursuit of basic science research with the potential to have measurable impacts on clinical care and patients living with chronic pain.

We would like to extend special thanks to Dr. Jeffrey Mogil for his time and effort in contributing to this article.

\section{References}

1. Chianta M, Guevara M. Pharmacogenetics and pain management: an opportunity to advance personalized patient care. MLO Med Lab Obs. 2014 Feb;46(2):9, 11.

2. Gureje O, Von Korff M, Simon GE, Gater R. Persistent pain and wellbeing: a World Health Organization Study in Primary Care. JAMA. 1998 Jul 8;280(2):147-51.

3. Dhalla IA, Mamdani MM, Sivilotti ML, Kopp A, Qureshi O, Juurlink DN. Prescribing of opioid analgesics and related mortality before and after the introduction of long-acting oxycodone. CMAJ. 2009 Dec 8;181(12):891-6.

4. Peng $P$, Choiniere $M$, Dion $D$, Intrater $H$, Lefort $S$, Lynch $M$, et al. Challenges in accessing multidisciplinary pain treatment facilities in Canada. Can J Anaesth. 2007 Dec;54(12):977-84.

5. Watt-Watson J, McGillion M, Hunter J, Choiniere M, Clark AJ, Dewar A, et al. A survey of prelicensure pain curricula in health science faculties in Canadian universities. Pain Res Manag. 2009 Nov-Dec;14(6):439-44.

6. Lynch ME, Schopflocher D, Taenzer P, Sinclair C. Research funding for pain in Canada. Pain Res Manag. 2009 Mar-Apr;14(2):113-5.

7. Lynch ME. The need for a Canadian pain strategy. Pain Res Manag. 2011 Mar-Apr;16(2):77-80.

8. Phillips CJ, Schopflocher D. Chronic Pain: A Health Policy Perspective (eds S. Rashiq, D. Schopflocher, P. Taenzer and E. Jonsson). Weinheim, Germany: Wiley-VCH Verlag GmbH \& Co. KgaA; 2008. Chapter 4, The Economics of Chronic Pain; p. 41-50.

9. Martin LJ, Hathaway G, Isbester K, Mirali S, Acland EL, Niederstrasser N, et al. Reducing Social Stress Elicits Emotional Contagion of Pain in Mouse and Human Strangers. Curr Biol. 2015 Feb 2;25(3):326-32.

10. Perkins JR, Lees J, Antunes-Martins A, Diboun I, McMahon SB, Bennett DL, et al. PainNetworks: a web-based resource for the visualisation of painrelated genes in the context of their network associations. Pain. 2013 Dec;154(12):2586 e1-12.

11. Wieskopf JS, Pan YX, Marcovitz J, Tuttle AH, Majumdar S, Pidakala J, et al. Broad-spectrum analgesic efficacy of IBNtxA is mediated by exon 11-associated splice variants of the mu-opioid receptor gene. Pain. 2014 Oct;155(10):2063-70.

12. Convertino M, Samoshkin A, Gauthier J, Gold MS, Maixner W, Dokholyan NV, et al. mu-Opioid receptor 6-transmembrane isoform: A potential therapeutic target for new effective opioids. Prog Neuropsychopharmacol 


\section{HeALTh SCIENCE INQUiRy}

Biol Psychiatry. 2014 Dec 6. pii: S0278-5846(14)00235-8.

13. Diatchenko L, Robinson JE, Maixner W. Elucidation of mu-Opioid Gene Structure: How Genetics Can Help Predict Responses to Opioids. Eur J Pain Suppl. 2011 Nov 11;5(2):433-8.

14. Fillingim RB, Wallace MR, Herbstman DM, Ribeiro-Dasilva M, Staud R. Genetic contributions to pain: a review of findings in humans. Oral Dis. 2008 Nov;14(8):673-82.

15. Linares OA, Daly D, Linares AD, Stefanovski D, Boston RC. Personalized oxycodone dosing: using pharmacogenetic testing and clinical pharmacokinetics to reduce toxicity risk and increase effectiveness. Pain Med. 2014 May;15(5):791-806.

Isabella Albanese

Isabella is a first year medical student at McGill University. She completed her Master's degree in Experimental Medicine at McGill, studying the role of Wnt signaling pathways in atherosclerotic vascular calcification. She aims to incorporate science journalism into her career as a physician and hopes to contribute to remedying the spread of scientific misinformation to the public in our current society. 